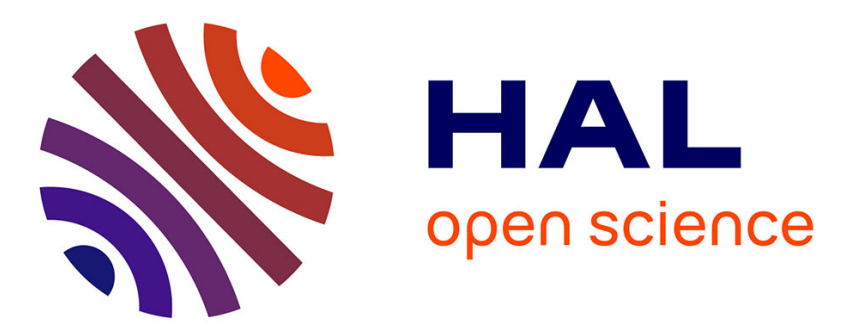

\title{
Magnetotransport in MgO-based magnetic tunnel junctions grown by molecular beam epitaxy (invited)
}

Stéphane Andrieu, F. Bonell, Thomas Hauet, François Montaigne, Lionel Calmels, Etienne Snoeck, P. Lefevre, F. Bertran

\section{- To cite this version:}

Stéphane Andrieu, F. Bonell, Thomas Hauet, François Montaigne, Lionel Calmels, et al.. Magnetotransport in MgO-based magnetic tunnel junctions grown by molecular beam epitaxy (invited). Journal of Applied Physics, 2014, 115 (17), pp.172610. 10.1063/1.4869824 hal-01282615

\section{HAL Id: hal-01282615 https://hal.science/hal-01282615}

Submitted on 16 Aug 2016

HAL is a multi-disciplinary open access archive for the deposit and dissemination of scientific research documents, whether they are published or not. The documents may come from teaching and research institutions in France or abroad, or from public or private research centers.
L'archive ouverte pluridisciplinaire HAL, est destinée au dépôt et à la diffusion de documents scientifiques de niveau recherche, publiés ou non, émanant des établissements d'enseignement et de recherche français ou étrangers, des laboratoires publics ou privés. 


\title{
MAGNETOTRANSPORT IN MGO-BASED MAGNETIC TUNNEL JUNCTIONS GROWN BY MBE
}

\author{
S. Andrieu ${ }^{1 *}$, F. Bonell ${ }^{1 *}$, T. Hauet ${ }^{1}$, F. Montaigne ${ }^{1}$, L. Calmels ${ }^{2}$, E. Snoeck ${ }^{2}$, P. \\ Lefevre $^{3}$, F. Bertran ${ }^{3}$ \\ 1 Institut Jean Lamour, Nancy University / CNRS, Bd des Aiguillettes, BP239, \\ 54506 Vandoeuvre-lès-Nancy, FRANCE \\ 2 CEMES, CNRS and Toulouse University, 29 rue Jeanne Marvig, \\ 31055 Toulouse, FRANCE \\ 3 Synchrotron SOLEIL-CNRS, L'Orme des Merisiers, Saint-Aubin, BP48, \\ 91192 Gif-sur-Yvette cedex, FRANCE
}

\begin{abstract}
The strong impact of MBE growth and Synchrotron Radiation characterization tools in the understanding of fundamental issues in nanomagnetism and spintronics is illustrated through the example of fully epitaxial MgO-based Magnetic Tunnel Junctions (MTJs). If ab initio calculations predict very high TMR in such devices, some discrepancy between theory and experiments still exists. The influence of imperfections in real systems has thus to be considered like surface contaminations, structural defects, unexpected electronic states, etc... The influence of possible oxygen contamination at the $\mathrm{Fe} / \mathrm{MgO}(001)$ interface is thus studied, and is shown to be not detrimental to TMR. On the contrary the decrease of dislocations density in the $\mathrm{MgO}$ barrier of MTJs using $\mathrm{Fe}_{1-\mathrm{x}} \mathrm{V}_{\mathrm{x}}$ electrodes is shown to significantly increase TMR. Finally, unexpected transport properties in $\mathrm{Fe}_{1-\mathrm{x}} \mathrm{Co}_{\mathrm{x}} / \mathrm{MgO} / \mathrm{Fe}_{1-\mathrm{X}} \mathrm{Co}_{\mathrm{x}}(001)$ are presented. With the help of spin and symmetry resolved photoemission and ab initio calculation, the TMR decrease for Co content higher than $25 \%$ is shown to come from the existence of an interface state and the shift of the empty $\Delta 1$ minority spin state towards the Fermi level.

* corresponding author : stephane.andrieu@univ-lorraine.fr

PACS numbers: 72.25.b, 73.40.Gk, 79.60.i, 81.15.Hi
\end{abstract}




\section{Introduction}

In 2001, huge Tunnel MagnetoResisance (TMR) was theoretically predicted in the single-crystalline $\mathrm{Fe} / \mathrm{MgO} / \mathrm{Fe}(001)$ system [1]. Such high TMR values were experimentally confirmed in $\mathrm{Fe} / \mathrm{MgO}$ or $\mathrm{Fe}_{1-\mathrm{X}} \mathrm{Co}_{\mathrm{x}} / \mathrm{MgO}(001)$ based Magnetic Tunnel Junction (MTJ) by several groups in the world since 2001. The basis of spin polarized transport in fully epitaxial MgO-based MTJ is explained by considering the particular electronic structure along the $\mathrm{BCC}(001)$ structure and the symmetry filtering of the $\mathrm{MgO}$ barrier [1]. However, the TMR observed in real systems is not as large as the TMR predicted theoretically. Many assumptions were thus proposed to account for lower values in experiments (impurities at the interfaces, vacancies in the barrier, surface states). The strategy of our group was to look systematically on the special properties of the MBE-grown MTJs and to answer to many questions: Is the interface as good as in the calculations [2-4]? Are there any impurities at the interface? What are the consequences of the interface doping with $\mathrm{C}$ or $\mathrm{O}$ [5]? What about defect in the $\mathrm{MgO}$ barrier [6]? Is there some interface electronic state [3,7]? What is its impact on the tunnelling process? To highlight these different points, we first studied the effect of $\mathrm{Fe} / \mathrm{MgO}$ interface doping with $\mathrm{O}$, showing that it does not lead to detrimental effect on the TMR. Second, the use of $\mathrm{Fe}_{1-\mathrm{x}} \mathrm{V}_{\mathrm{x}}$ electrodes instead of $\mathrm{Fe}$ (increasing $\mathrm{x}$ decreases the misfit with $\mathrm{MgO}$ ) allows us to clearly show that the dislocation density in the $\mathrm{MgO}$ barrier strongly affects the TMR. But the most contradictory and intriguing results were obtained on the transport properties observed on $\mathrm{Co}_{\mathrm{x}} \mathrm{Fe}_{1-\mathrm{x}} / \mathrm{MgO}(001)$ based Magnetic Tunnel Junction by several groups [7]. In this paper, we detailed these different points and try to quantify these effects on the amplitude of TMR. The main physics that govern the transport in epitaxial MgO-based MTJs is recall in the first part of the paper. In the second part the effect of $\mathrm{O}$ contamination at the $\mathrm{Fe} / \mathrm{MgO}$ interface is explored. In the third part we focus on the influence of misfit dislocations in the $\mathrm{MgO}$ barrier on the magneto-transport. Finally, the special and unexpected properties observed in $\mathrm{Fe}_{1-\mathrm{X}} \mathrm{Co}_{\mathrm{x}}-$ $\mathrm{MgO}$ based MTJs are examined in the last part.

\section{I - Magneto-transport theory in MgO-based MTJs}

A magnetic tunnel junction consists in two ferromagnetic electrodes separated by a nanometer-thick insulating barrier. To obtain a non-negligible tunnelling current 
applying a voltage bias to the structure, the thickness of the barrier has to be in the nanometer range since the intensity of the tunneling current decreases exponentially with it. The TMR is usually defined in terms of resistance $\mathrm{R}$ or conductance $\mathrm{G}$ in $\mathrm{P}$ and AP configuration as:

$$
\mathrm{TMR}=\frac{\mathrm{R}_{\mathrm{AP}}-\mathrm{R}_{\mathrm{P}}}{\mathrm{R}_{\mathrm{P}}}=\frac{\mathrm{G}_{\mathrm{P}}-\mathrm{G}_{\mathrm{AP}}}{\mathrm{G}_{\mathrm{AP}}}
$$

Four basic points have to be noticed to understand the huge TMR obtained in MgObased MTJs [1,8]:

(i) The tunnelling current in the coherent regime (without electron scattering by defects or interfaces) is established keeping the spin and symmetry of the electronic states.

(ii) The current is roughly perpendicular to the interface that is along (001) (inclined trajectories are more attenuated, especially for thick $\mathrm{MgO}$ barrier).

(iii) There is no density of state (DOS) for minority spin along (001) direction , $\Delta$ in the reciprocal lattice. In other words, $\Delta 1$ states have a half-metallic behaviour.

(iv) The other channels of conduction via $\Delta 2, \Delta 2^{\prime}$ and $\Delta 5$ states are strongly attenuated by $\mathrm{MgO}$. The $\mathrm{MgO}$ barrier plays the role of symmetry filter.

To go further, let's consider a weak periodic potential of the electrodes [1]. The electrons are thus described by Bloch wave functions $\psi(r)=u_{k}(r) e^{i k r}$ where $u_{k}(r)$ gets the potential symmetry. First, the probability of finding the electron on the other side of the tunnel barrier is exponentially decreasing with the thickness $d$ of the latter, but this is not the only reason for that. Indeed, the potential can be decomposed in Fourier series with reciprocal lattice vector $G$, and depending on the value of $G$, the symmetry of the wave function changes: $\Delta 1$ for $G=0, \Delta 5$ for $G=2 \pi / a, \Delta 2$ for $G=2 \pi \sqrt{2} / a$. The decay term in the barrier then depends on $G$ as:

$$
\mathrm{T} \propto \exp -2 \kappa_{G} \mathrm{~d}
$$

The decay rate in the barrier is thus much lower for a $\Delta 1$ state than for $\Delta 2$ and $\Delta 5$ states. As the decay for $\Delta 2$ symmetry is strong, the conductance is almost entirely due to $\Delta 1$ states in the $\mathrm{P}$ configuration and to $\Delta 5$ states in AP configuration in $\mathrm{Fe} / \mathrm{MgO} / \mathrm{Fe}$. Therefore, the conductance decay with the $\mathrm{MgO}$ thickness is of $\Delta 1$ type for $\mathrm{P}$ configuration, and of $\Delta 5$ type for AP. Thus, the TMR should increase with the thickness of $\mathrm{MgO}[9,10]$, but a too large $\mathrm{MgO}$ thickness may lead to undetectable tunnel currents. 
A thickness around 12 atomic planes is a good compromise. Very high TMRs are calculated, around $1000 \%$ at $0 \mathrm{~K}$ for $\mathrm{Fe} / \mathrm{MgO} / \mathrm{Fe}(001)$. Even larger TMR values are predicted using equimolar FeCo electrodes. Indeed, there are no more $\Delta 5$ states at the Fermi level for majority spin, leading to theoretical TMR as large as 6000\% (using equimolar FeCo ordered alloy) [11].

On the experimental point of view, very large TMR were actually observed, but not as large as predicted. The best reported values were $480 \%$ at $20 \mathrm{~K}$ in MBE grown $\mathrm{Fe} / \mathrm{MgO} / \mathrm{Fe}(001)$ [8], 530\% in MBE grown $\mathrm{Fe}_{0.75} \mathrm{Co}_{0.25} / \mathrm{MgO} / \mathrm{Fe}_{0.75} \mathrm{Co}_{0.25}(001)$ [7], and around $1100 \%$ in $\mathrm{FeCoB} / \mathrm{MgO} / \mathrm{FeCoB}$ at $5 \mathrm{~K}$ [12]. The main theoretical hypotheses which were explored to explain such discrepancy were (i) $\mathrm{C}$ or $\mathrm{O}$ contamination the $\mathrm{MgO}$ interface and (ii) vacancies in the $\mathrm{MgO}$ barrier. The possibility of interface state existence and influence is also pointed out. We looked at these different possibilities in real systems.

\section{II - Oxygen doping at the $\mathrm{Fe} / \mathrm{MgO}(001)$ interface}

The first hypothesis explored by theorists to explain the differences between experiments and theory is the presence of impurities at the interfaces. Ab initio calculations were carried out by several groups $[13,14]$ to look at the influence of $\mathrm{O}$ at the $\mathrm{Fe} / \mathrm{MgO}$ interface. They all show a strong TMR decrease due to oxygen. To clarify this point, tunneling transport in MTJs has been investigated by carefully doping the $\mathrm{Fe} / \mathrm{MgO}$ interface with $\mathrm{O}$ [5]. The $\mathrm{O}$ deposition was performed on $\mathrm{Fe}(001)$ surfaces using $\mathrm{O}_{2}$ gaz delivered by a leak valve. The $\mathrm{O}$ adsorption kinetics was recorded in real time using X-Ray Photoemission Spectroscopy (XPS using a Al anode), and the surface morphology using STM after the growth. A summary of the results are given in fig.1. Without annealing, oxygen atoms layer is disordered up to around 1ML. A phase transition occurs above this thickness leading to $\mathrm{FeO}$ islands creation that perfectly match the underneath $\mathrm{Fe}(001)$ lattice (fig.1a). Another very interesting point is that, by annealing, a disordered $1 \mathrm{ML} \mathrm{O}$ layer on $\mathrm{Fe}(001)$ leads to a perfect $\mathrm{O} 1 \mathrm{x} 1$ lattice arrangement on top of Fe, as shown by STM. We thus looked at the effect of both interfacial disordered and ordered $\mathrm{O}$ layer on the magneto-transport properties. A TMR decrease with $\mathrm{O}$ doping is actually observed, but it remains low compared to the 
calculations and does not seem to be the real origin of the disagreement between measured and calculated TMR.

\section{III - Influence of misfit dislocations in the $\mathrm{MgO}$ barrier}

Another way to improve our understanding of magneto-transport in real systems is to consider the presence of defects in the $\mathrm{MgO}$ barrier. On the theoretical point of view, the effect of vacancies in $\mathrm{MgO}$ was considered [15,16], whereas more extended defects are difficult to implement in the calculations. In real MgO-based MTJs, such vacancies density is certainly small and was not clearly quantified. However, another type of defects in the barrier has been clearly identified, i.e. dislocations arising from the $4 \%$ misfit between $\mathrm{Fe}$ and $\mathrm{MgO}$. Such a misfit leads to a very high density of dislocations (every 5nm) [6]. Moreover, as well-known in FCC materials, the dislocations in $\mathrm{MgO}$ are inclined by $45^{\circ}$ (dislocation + glide plane) (fig.2a-b). So far it is impossible to perform ab initio calculations for such extended defects. To estimate their influence on the transport, Fe was replaced by $\mathrm{BCC} \mathrm{Fe}_{1-\mathrm{x}} \mathrm{V}_{\mathrm{x}}$ alloys having larger lattice spacing than pure $\mathrm{Fe}$. By increasing the concentration of $\mathrm{V}$, the misfit is thus reduced and the dislocation density should therefore decrease in the barrier. Using High Resolution Transmission Electron Microscopy (HRTEM) and strain mapping technique, we actually observed a decrease of the dislocation density in the $\mathrm{MgO}$ barrier when increasing the $\mathrm{V}$ content [6]. However, we verified by spin-resolved photoemission [6] that the spin polarization of $\mathrm{Fe}_{1-\mathrm{x}} \mathrm{V}_{\mathrm{x}}$ also decreases with $\mathrm{V}$ content, and should reduce the TMR. To disentangle these two effects, MTJs have been grown with two different magnetic electrodes, $\mathrm{Fe}_{1-\mathrm{x}} \mathrm{V}_{\mathrm{x}}$ on one hand and $\mathrm{Fe}$ on the other. Starting growth by the $\mathrm{Fe}$ electrode, the dislocation density in $\mathrm{MgO}$ is fixed by the $4 \%$ misifit between $\mathrm{Fe}$ and $\mathrm{MgO}$. The second electrode is $\mathrm{Fe}_{1-\mathrm{x}} \mathrm{V}_{\mathrm{x}}$ alloys for $\mathrm{x}$ ranging from 0 to $30 \%$. As expected, TMR decreases when increasing $x$, due to the polarization decrease of the $\mathrm{Fe}_{1-\mathrm{x}} \mathrm{V}_{\mathrm{x}}$ alloy [6]. By starting then the growth with $\mathrm{Fe}_{1-\mathrm{x}} \mathrm{V}_{\mathrm{x}}$ electrode, the dislocation density is thus reduced compared to pure Fe. The choice of the Fe second electrode is important to keep the same couple of electrodes to get similar initial and final electronic states for the conduction process. A TMR increase was observed up to $10 \%$ of $\mathrm{V}$, meaning that the $\mathrm{Fe}_{1-\mathrm{x}} \mathrm{V}_{\mathrm{x}}$ polarization decrease was largely offset by improving the $\mathrm{MgO}$ barrier crystalline quality (Fig.2c). This is a clear experimental evidence of the misfit dislocations influence on tunneling in MTJs [6]. 
But we can go further since TMR variations are roughly linear with $\mathrm{V}$ content above $8 \% \mathrm{~V}$ for both for $\mathrm{Fe} / \mathrm{MgO} / \mathrm{Fe}_{1-\mathrm{x}} \mathrm{V}_{\mathrm{x}}$ (top) and for $\mathrm{Fe}_{1-\mathrm{x}} \mathrm{V}_{\mathrm{x}} / \mathrm{MgO} / \mathrm{Fe}$ (top) (fig.2c). This can be understood considering the variation of both dislocation density and spin polarization with $\mathrm{V}$ content. The $\mathrm{TMR}(\mathrm{x})$ curve obtained on $\mathrm{Fe} / \mathrm{MgO} / \mathrm{Fe}_{1-\mathrm{x}} \mathrm{V}_{\mathrm{x}}$ (top) accounts for the variation of the polarization, the dislocation density being roughly constant. Such a variation is almost similar for $\mathrm{x}>8 \%$ in the case of $\mathrm{Fe}_{1 \text { - }}$ ${ }_{\mathrm{x}} \mathrm{V}_{\mathrm{x}} / \mathrm{MgO} / \mathrm{Fe}$ (top), which means that the main parameter that thus varies with $\mathrm{x}$ is the polarization. This is finally not surprising considering that the dislocation density is related to the inverse of the misfit. So for large misfit (from 0 to $8 \% \mathrm{~V}$ ), the dislocation density varies significantly in the $\mathrm{MgO}$ barrier and the $\mathrm{TMR}$ of $\mathrm{Fe}_{1-\mathrm{x}} \mathrm{V}_{\mathrm{x}} / \mathrm{MgO} / \mathrm{Fe}$ (top) MTJ increases. For larger $\mathrm{V}$ content $(x>8 \%)$, the misfit becomes smaller, so the distance between dislocations increases a lot. The fact that this former $\operatorname{TMR}(\mathrm{x})$ variation is thus close to the case of $\mathrm{Fe} / \mathrm{MgO} / \mathrm{Fe}_{1-\mathrm{x}} \mathrm{V}_{\mathrm{x}}$ (top) means that the main parameter that decreases the TMR is then the spin polarization, and the dislocations effect becomes negligible because of the too long distance between them. This is an opportunity to estimate what should be the TMR in $\mathrm{Fe} / \mathrm{MgO} / \mathrm{Fe}(001)$ without dislocation effect, just looking at the $\operatorname{TMR}(\mathrm{x})$ linear variation intercept with $\mathrm{x}=0$ in $\mathrm{Fe}_{1-\mathrm{x}} \mathrm{V}_{\mathrm{x}} / \mathrm{MgO} / \mathrm{Fe}$ (top) MTJs. We obtain around $290 \%$ to compare to the $190 \%$ routinely obtained on $\mathrm{Fe} / \mathrm{MgO} / \mathrm{Fe}$ (at room temperature). This means that in this case the dislocations in the $\mathrm{MgO}$ barrier in contact with Fe lower the TMR by a factor around 1.5 at room temperature.

\section{IV - Do $\mathrm{Fe}_{1-\mathrm{x}} \mathrm{Co}_{\mathrm{x}}$ electrodes increase the TMR?}

$\mathrm{FeCo}(\mathrm{B}) / \mathrm{MgO} / \mathrm{FeCo}(\mathrm{B})$ (001) multilayers fabricated by molecular beam epitaxy (MBE) or sputtering deposition are widely utilized for their high spin current injection because of the huge TMR predicted by ab initio calculations (6000\% at 0K [11]). It should be noted that these calculation were performed in the case of the equimolar and B2 ordered $\mathrm{Fe}_{0.5} \mathrm{Co}_{0.5}$ alloy and for pure BCC Co. However, two groups observed that epitaxial $\mathrm{Fe}_{0.5} \mathrm{Co}_{0.5} / \mathrm{MgO} / \mathrm{Fe}(001)$ and $\mathrm{Fe} / \mathrm{MgO} / \mathrm{Fe}(001)$ MTJs exhibit the same TMR [7,17]. Moreover, the B2 order assumed in [11] is not observed. And finally, if Lee \& al [18] observed a TMR increase up to $25 \%$ Co, a TMR drop down is found for higher Co content. These authors explained their result by the poor crystallization of the stack after annealing for high Co content. We have prepared similar $\mathrm{Fe}_{1-\mathrm{x}} \mathrm{Co}_{\mathrm{x}} \mathrm{MTJ}$ grown by MBE for Co content in the range $0-70 \%$ (for higher content, the $\mathrm{Fe}_{1-\mathrm{x}} \mathrm{Co}_{\mathrm{x}}$ alloys are no longer 
BCC, but HCP) and the same result was obtained (fig.3). The origin of this anomaly has been determined by performing spin- and symmetry-resolved photoemission experiments at SOLEIL synchrotron on $\mathrm{Fe}_{1-\mathrm{x}} \mathrm{Co}_{\mathrm{x}}$ alloys coated with $\mathrm{MgO}$ [7].

The $\mathrm{Fe}_{1-\mathrm{x}} \mathrm{Co}_{\mathrm{x}}$ alloys were grown by co-evaporation of $\mathrm{Fe}$ and $\mathrm{Co}$ sublimated from Knudsen cells. The epitaxy relationship, growth rates and stoichiometry were checked by using Reflexion High Energy Electron Diffraction (RHEED) during the growth of pure $\mathrm{Fe}$, pure $\mathrm{Co}$ or $\mathrm{Fe}_{1-\mathrm{x}} \mathrm{Co}_{\mathrm{x}}$ alloys on $\mathrm{Fe}(001)$ buffer layers. One should note moreover that to get large TMR the $\mathrm{Fe}_{1-\mathrm{x}} \mathrm{Co}_{\mathrm{x}}$ should be in the $\mathrm{BCC}$ structure. The crystalline structure of bulk $\mathrm{Fe}_{1-\mathrm{x}} \mathrm{Co}_{\mathrm{x}}$ layers is known to be $\mathrm{BCC}$ up to $\mathrm{x}$ around $70 \%$, and HCP for higher Co content. However, it is possible to stabilize the BCC structure for the whole Co concentration range by growing very thin $\mathrm{Fe}_{1-\mathrm{x}} \mathrm{Co}_{\mathrm{x}}$ alloys on a $\mathrm{BCC}$ Fe(001) buffer layer, as verify by using RHEED. Micron-size MTJs were patterned by optical lithography and Ar ion milling. Fig.3 displays the TMR variations as a function of $x$, at $20 \mathrm{~K}$. As explained in the introduction, the TMR increases continuously from $\mathrm{x}=0$ to $\mathrm{x}=0.25$, but a dramatic decrease is observed for larger values of $\mathrm{x}$, exactly like in sputtered $\mathrm{FeCoB} / \mathrm{MgO} / \mathrm{FeCoB}$ MTJs [17]. Since $\mathrm{MgO}$ quality in our MBE-grown MTJs does not change with Co concentration, we can conclude that poor $\mathrm{MgO}$ crystallization is not the main origin of the observed TMR variations as expected in Ref. [18]. To understand this general behavior, we need information on the real electronic band structure, spin and symmetry resolved. Spin-resolved photoemission is a well-known tool to get the spin-resolved DOS. A typical experiment is to measure the photo-emitted current in two opposite magnetic configurations in order to eliminate the MOTT asymmetry. Since we are interested in $\Delta$ states, the sample normal axis is oriented along the detector axis, and the detector aperture was decreased at its minimum $\left(1.8^{\circ}\right)$. The photon energy was fixed in the range $30-60 \mathrm{eV}$ for which the absorption cross section is maximum for $3 \mathrm{~d}$ metals. It is also possible in some case to get symmetry information using the polarization of the impinging photons. Indeed, the electron extraction from an orbital during the photoemission process obeys to selection rules that can be formulated using symmetry rules [18]. Thus, the symmetry of the explored orbital has to be the same as the symmetry of the photon electric field. We thus used the linear polarization of the photons with a sample + detector + photon beam geometry showed in fig.4. For the so-called $s$ polarization (E-field perpendicular to the incident and reflected trajectory plane in optics), the electric field is in the plane of the sample for this geometry. The axis defined by the photon electric field is thus a symmetric axis, and the perpendicular 
axis an anti-symmetric axis. $\Delta 5$ states possess this symmetry and can thus be excited. However, this is not true for $\Delta 1$ states who got a revolution symmetry axis perpendicular to the surface ( $\Delta 1$ is a convolution of $s, p_{z}$ and $d_{z}{ }^{2}$ orbitals). To excite these states, the photon electric field vector should have a non-zero projection along $\Delta$. This is the case for a $p$ polarization (E-field in the incident and reflected trajectory plane in optics). A typical experiment is thus performed by measuring the photo-emitted current on the same sample for the two photon E-field polarization. These experiments were performed on a series of $\mathrm{Fe}_{1-\mathrm{x}} \mathrm{Co}_{\mathrm{x}}$ alloys grown on $\mathrm{Fe}(001)$ buffer layers $(\mathrm{x}=0,25$, $37.5,50,62.5,75,100 \%)$. The observed transitions on the photoemission spectra (PES) were thus identified with respect to their spin and symmetry [7]. Above 50\% Co a new $\Delta_{1}$ state is observed below $E_{F}$ for minority spin channel and using High Resolution PES this state was identified to be a surface state. Such a state is thus observed to be below the Fermi level for Co content above $30 \%$ and may play a significant role in the magneto-transport process in MTJs since it breaks the half-metallic magnetic behavior of the $\Delta 1$ states. However a key point was to verify if this surface state still exist when growing $\mathrm{MgO}$ on top of $\mathrm{Fe}_{1-\mathrm{x}} \mathrm{Co}_{\mathrm{x}}$ (becoming an interface sate). We have shown that it is actually true for pure $\mathrm{Co}$, and we checked it recently on a $\mathrm{Fe}_{0.25} \mathrm{Co}_{0.75}$ layer covered by $\mathrm{MgO}$. The results are shown in fig. 5 for photon energy of $50 \mathrm{eV}$. The reduction of PES between $p$ and $s$ photon polarization for majority spin informs us on the $\Delta 1 \uparrow$ symmetry of this excited state. This is consistent with ab initio calculations we performed for this purpose [25] (for bulk chemically disoredered $\mathrm{BCC} \mathrm{Fe}_{1-\mathrm{x}} \mathrm{Co}_{\mathrm{x}}$ alloys). $\mathrm{A} \Delta 5 \downarrow$ is also clearly identified looking at the minority spin PES, also in good agreement with calculations. Finally, the interface state is clearly observed around $0.4 \mathrm{eV}$ below $\mathrm{E}_{\mathrm{F}}$ on minority spin PES. Its intensity is strongly reduced using $s$ polarization compared to $p$ one, indicating a $\Delta 1$ symmetry. It should be noted moreover that this interface state is certainly not the only reason for decreasing the TMR for large Co content. Indeed, we also observed that the empty $\Delta 1 \downarrow$ at $1 \mathrm{eV}$ above $\mathrm{E}_{\mathrm{F}}$ in BCC Fe starts to slightly cross $\mathrm{E}_{\mathrm{F}}$ for Co content above $30 \%$. The transport properties are thus explained by considering both effects (fig.3) [7].

\section{V-Conclusions}

The origin of the discrepancy between calculated and observed TMR in MgObased magnetic tunnel junction is thus certainly not due to a unique effect, but probably 
to a combination of several undesired phenomena. The interface contamination with $\mathrm{O}$ and $\mathrm{C}$ participates to a TMR decrease, but in a limited way. The impact of dislocations in the $\mathrm{MgO}$ barrier is certainly more important, since TMR is observed to increase when decreasing the dislocation density even for $\mathrm{Fe}_{1-\mathrm{x}} \mathrm{V}_{\mathrm{x}}$ electrodes less spin polarized than Fe. The impact of interface state (since surface state on (001) BCC surface almost always exist) can be very strong and should be taken into account in every studied system. But ab initio calculations performed considering $\mathrm{Fe}_{1-\mathrm{x}} \mathrm{Co}_{\mathrm{x}}$ electrodes for the whole Co concentration range also showed us that special feature on the bulk electronic structure may lead to detrimental effect on the TMR. Now $\mathrm{Fe}_{1-\mathrm{x}} \mathrm{Co}_{\mathrm{x}}-\mathrm{MgO}$ based MTJs are commonly used in various topics in spintronics. One very promising route is to prepare such MTJs with perpendicular magnetization [19] for many reasons, the most important being the decrease of critical current for changing the magnetization by spin transfer torque. But since a few years, a new concept for manipulating the magnetization using an electrical field is explored. The demonstration of such effect was performed in 2007 by tuning the magnetic anisotropy with an applied field [20]. Subsequent studies confirmed these results [21] and we recently observed very strong effect of the electric field in the $\mathrm{MgO}$ barrier on the perpendicular magnetic anisotropy of a 5 monolayer thick Fe film inserted in a MTJ [22]. However, the physical explanation of this huge effect is definitely not established [22,23]. In particular, a link between perpendicular magnetic anisotropy and the existence of quantum well states has been established [24]. Thus, the role of interface states or/and quantum well states should be explored in details in magnetic tunnel junctions in the near future. 


\section{References}

[1] W.H.Butler, X.G.Zhang, T.C.Schulthess, J.M.MacLaren, Phys. Rev. B 63, 054416 (2001); J.Mathon \& A.Umerski, Phys. Rev. B 63, 220403 (2001)

[2] M. Sicot, S. Andrieu, P. Turban, Y. Fagot-Révurat, A. Tagliaferri, C. de Nadai, N.B. Brookes, F. Fortuna, F. Bertran, Phys. Rev. B, 68, 184406, (2003)

[3] C. Tiusan, M. Sicot, J. Faure-Vincent, M. Hehn, C. Bellouard, F. Montaigne, S. Andrieu, A.Schuhl, J. Phys.: Condens. Matter 18 , 941-956 (2006)

[4] V. Serin, S. Andrieu, R. Serra, F. Bonell, C. Tiusan, L. Calmels, M. Varela, J.S. Pennycook, E. Snoeck, M. Walls, C. Colliex, Phys. Rev. B 79, 144413, (2009)

[5] F. Bonell, S. Andrieu, A.M. Bataille, C. Tiusan, G. Lengaigne, Phys. Rev. B, 79, 224405, (2009)

[6] F. Bonell, S. Andrieu, C. Tiusan, and F. Montaigne, E. Snoeck, B. Belhadji, L. Calmels, F. Bertran, P. Le Fèvre, and A. Taleb-Ibrahimi, Phys. Rev. B, 82, 092405 (2010)

[7] F. Bonell, T. Hauet, S. Andrieu, F. Bertran, P. Le Fèvre, L. Calmels, A. Tejeda, F. Montaigne, B. Warot-Fonrose, B. Belhadji, A. Nicolaou, A. Taleb-Ibrahimi, Phys. Rev. Lett., 108, 176602 (2012)

[8] Molecular Beam Epitaxy: From Quantum Wells to Quantum Dots. From Research to Mass Production Chapter 20: Epitaxial Magnetic Layers Grown by MBE : Model Systems to Study the Physics in Nanomagnetism and Spintronic K. Dumesnil \& S. Andrieu, Ed. M. Henini, ELSEVIER (2012)

[9] S. Yuasa, T. Nagahama, A. Fukushima, Y. Suzuki, K. Ando, Nat. Mater. 3, 868 (2004)

[10] C. Heiliger, P. Zahn, B.Y. Yavorsly, I. Mertig, Phys. Rev. B 77, 224407 (2008)

[11] X.G. Zhang \& W.H. Butler, Phys. Rev. B 70, 172407 (2004)

[12] S.Ikeda, J.Hayakawa, Y.Ashizawa, Y.Lee, K.Miura, H. Hasegawa, M.Tsunoda, F. Matsukura, H.Ohno, Appl. Phys. Lett. 93, 082508 (2008)

[13] X.G.Zhang, W.H.Butler \& A.Bandyopadhyay, Phys. Rev. B 68, 092402 (2003)

[14] B.D.Yu \& J.S.Kim, Phys.Rev.B 73, 125408 (2006)

[15] J.P.Velev, K.D. Belashchenko, S.S. Jaswal \& E.Y.Tsymbal, Appl. Phys. Lett. 90, 072502 (2007)

[16] X.G.Zhang \& W.H.Butler, Phys. Rev. B 70, 172407 (2004)

[17] S. Yuasa, T. Katayama, T. Nagahama, A. Fukushima, H. Kubota, Y. Suzuki, K. Ando, Appl. Phys. Lett. 87, 222508 (2005)

[18] Y. M. Lee, J. Hayakawa, S. Ikeda, F. Matsukura, H. Ohno, Appl. Phys. Lett. 90, 212507 (2007)

[19] C.-H. Lambert, A. Rajanikanth, T. Hauet, S. Mangin, E.E. Fullerton, S. Andrieu, Appl. Phys. Lett. 102, 122410 (2013)

[20] M. Weisheit, S. Fahler, A. Marty, Y. Souche, C. Poinsignon \& D. Givord, Science 315, 349 (2007)

[21] T. Maruyama, Y. Shiota, T. Nozaki, K. Ohta, N. Toda, M. Mizuguchi, A.A. Tulapurka, T. Shinjo, M. Shiraishi, S. Mizukami, Y. Ando, Y. Suzuki, Nature Nanotechnology 4, 158 (2009)

[22] A. Rajanikanth, T.Hauet, F.Montaigne, S.Mangin, S.Andrieu, Appl. Phys. Lett. 103, $062402(2013)$

[23] Y. Shiota, F. Bonell, S. Miwa, N. Mizuochi, T. Shinjo, Y Suzuki, Appl. Phys. Lett. 103, 082410 (2013)

[24] M. Przybylski, M. Dąbrowski, U. Bauer, M. Cinal, J. Kirschner, J. Appl. Phys. 111, 07C102 (2012)

[25] B. Belhadji and L. Calmels, Phys. Rev. B 83, 092401 (2011) 


\section{Figure Captions}

Figure 1: a) Scanning Tunneling Microscopy image of a (001) Fe surface covered by 1.2 $\mathrm{ML}$ of oxygen. FeO islands form after the Fe surface was covered by O. b) TMR variation with the $\mathrm{O}$ coverage at the $\mathrm{Fe} / \mathrm{MgO}$ interface (see [6]).

Figure 2: a) HRTEM image of a $\mathrm{Fe} / \mathrm{MgO} / \mathrm{Fe}(001)$ stack where a dislocation in the $\mathrm{MgO}$ layer is highlighted. B) Corresponding strain image showing the core of the dislocations (bright). c) TMR variation with $\mathrm{V}$ content $\mathrm{x}$ for two series of MTJs with Fe1-xVx as a top or bottom electrode. The dashed lines show the variation and help to extrapolate the TMR value for $\mathrm{x}=0$ without dislocations (see text).

Figure 3: TMR variation at $20 \mathrm{~K}$ with Co content for a series of $\mathrm{Fe} 1-\mathrm{xCox} / \mathrm{MgO} / \mathrm{Fe} 1-$ xCox (001) MTJs. The TMR increase at low Co content is consistent with calculation, whereas TMR decreases above $25 \%$ Co due to the Interface State (IS) and empty bulk $\Delta 1 \downarrow$ band that cross the Fermi level for large Co content.

Figure 4: scheme of the symmetry selection rules between the photon E-Field and the orbitals. For s polarization, only $\Delta 5$ orbitals have the E-Field symmetry whereas for $\mathrm{P}$ polarization the photon E-Field can be projected along (100) and (001) allowing respectively $\Delta 5$ and $\Delta 1$ states excitation.

Figure 5: spin resolved photoemission spectra (PES) obtained on $\mathrm{Fe} 0.25 \mathrm{Co} 75 \%$ covered by $1.2 \mathrm{ML}$ of $\mathrm{MgO}$ using the two $\mathrm{s}$ and $\mathrm{p}$ photon E-Field polarizations. The increase of PES below $-3 \mathrm{eV}$ is due to the beginning of MgO DOS. In majority spin channel (left), the PES just below EF is strongly attenuated meaning that the symmetry is $\Delta 1$, as expected according to bulk calculations. In minority spin channel, the transition around $-1 \mathrm{eV}$ is not reduced and is identified to a $\Delta 5 \downarrow$ state which actually corresponds to a bulk band. The transition at $-0.4 \mathrm{eV}$ is the interface state identified as a $\Delta 1 \downarrow$ state. 

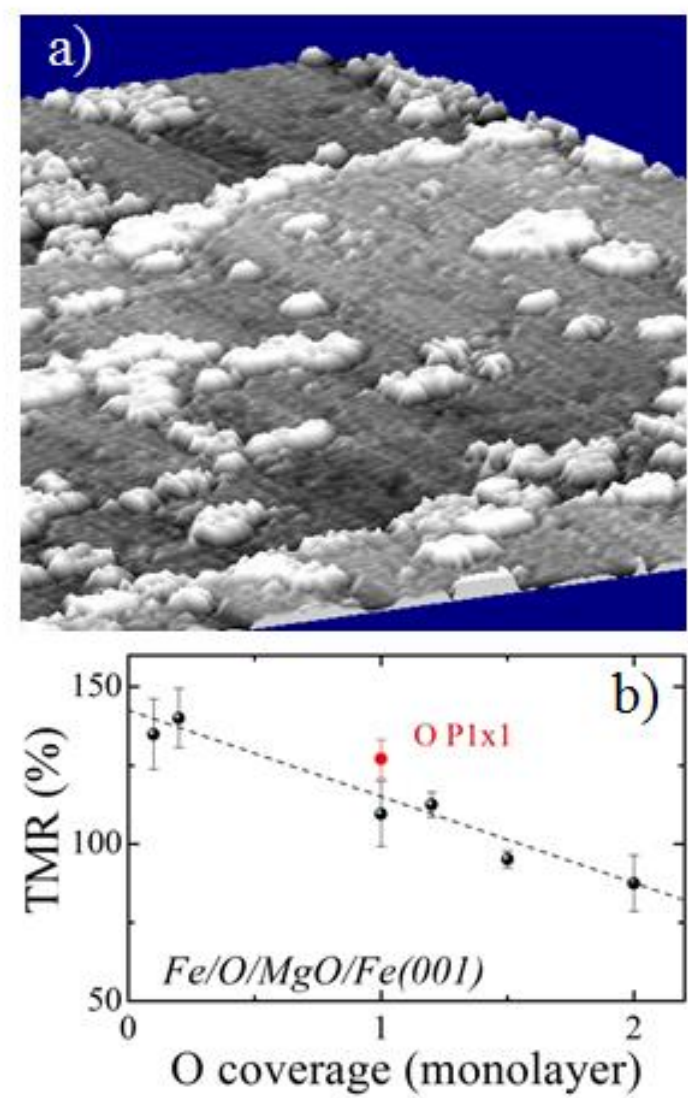

Figure 1 

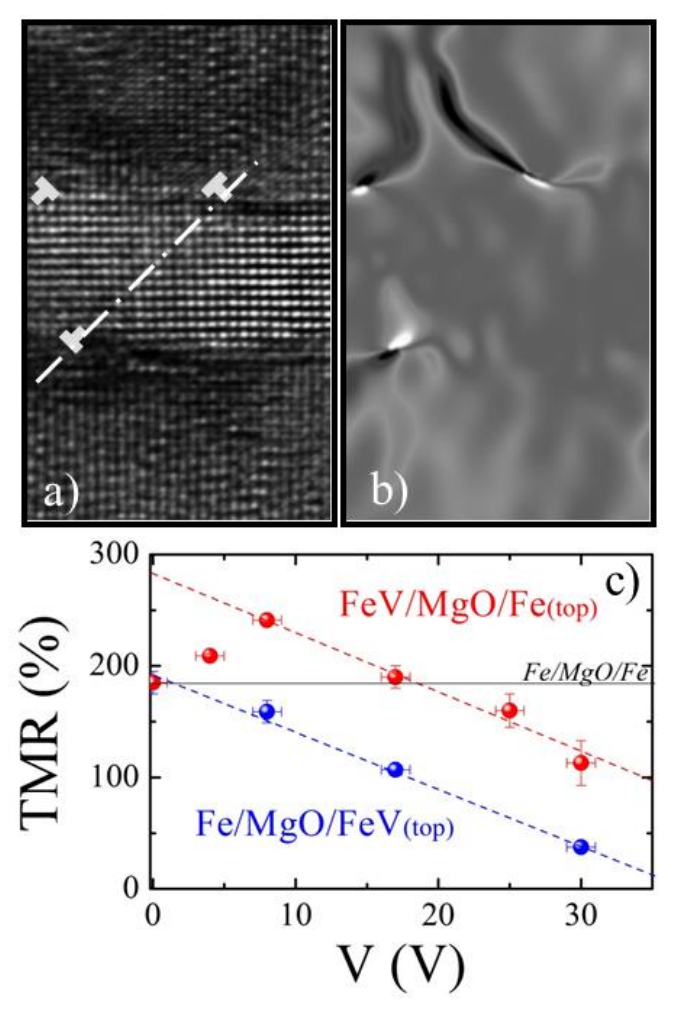

Figure 2

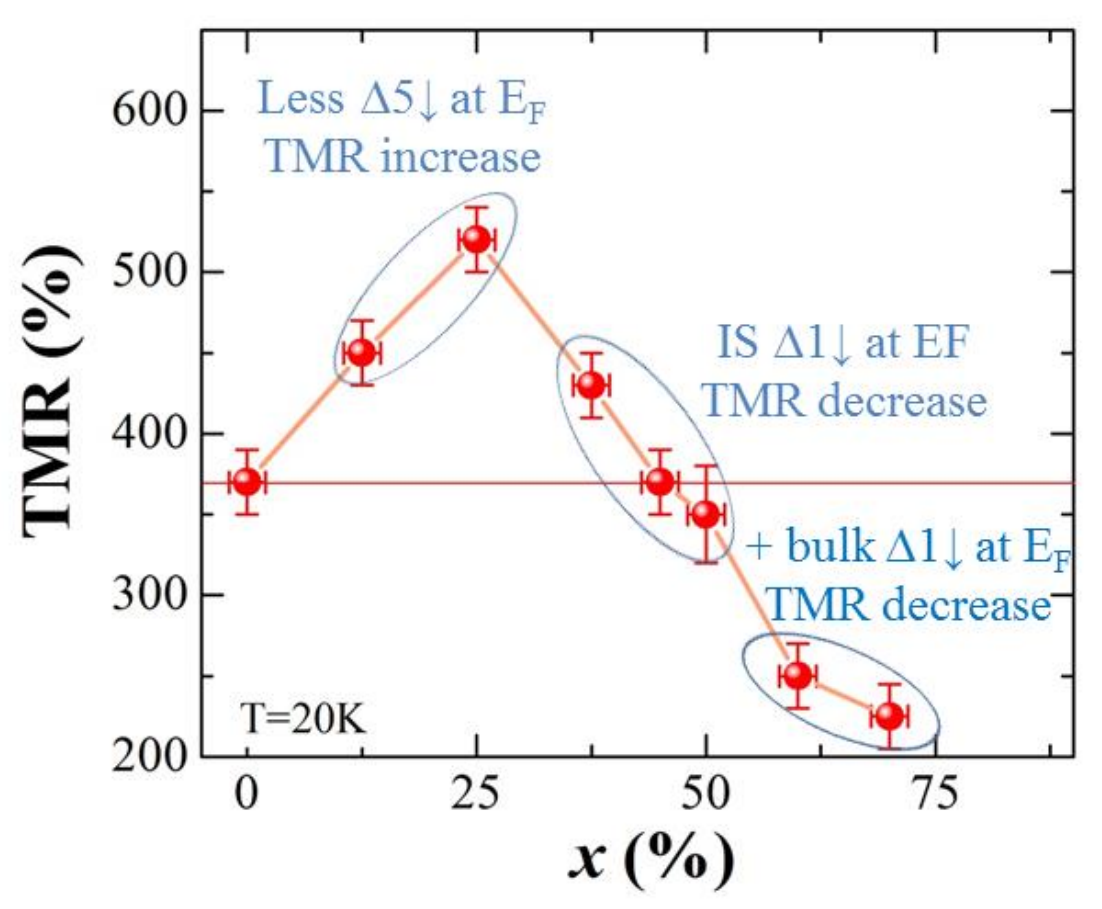

Figure 3 


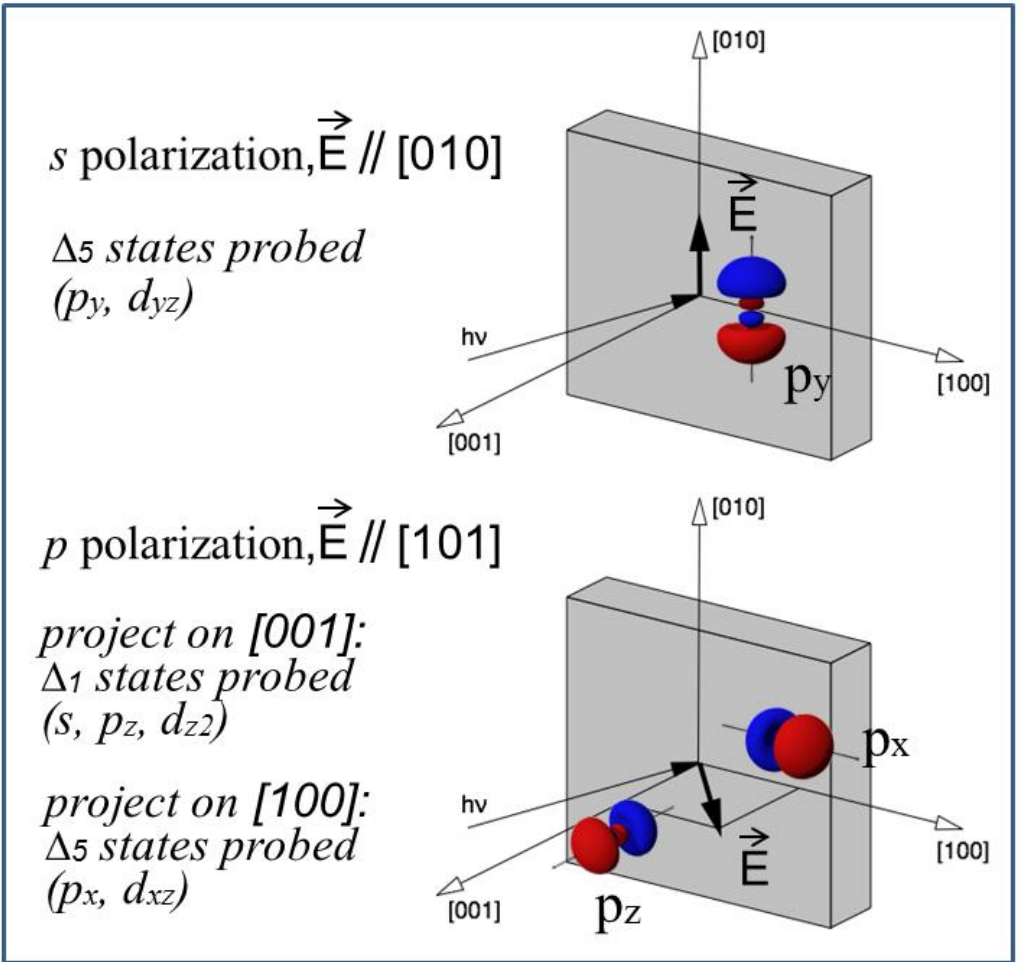

Figure 4

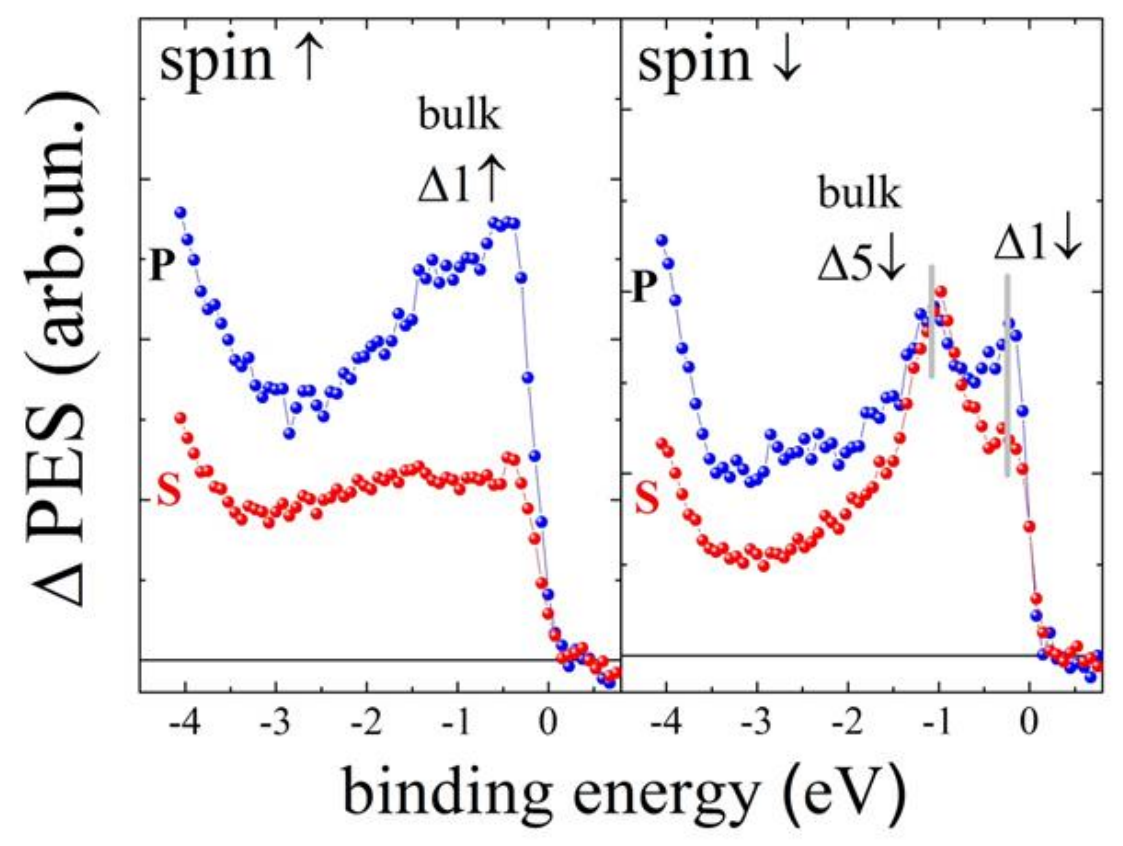

Figure 5 